Check for updates

Cite this: RSC Adv., 2017, 7, 55796

\title{
Synthesis and characterization of aniline-dimer- based electroactive benzoxazine and its polymer
}

\begin{abstract}
Shuliang Li, (D) Chunxia Zhao, (D) * Haolan Gou, Hui Li, Yuntao Li* and Dong Xiang
An electroactive aniline-dimer-based benzoxazine (BA-PADPA) was prepared from bisphenol $A, p-$ aminodiphenylamine (PADPA), and paraformaldehyde. The structure of BA-PADPA was successfully confirmed by fourier transform infrared spectroscopy, and ${ }^{1} \mathrm{H}-\mathrm{NMR}$ and ${ }^{13} \mathrm{C}-\mathrm{NMR}$ spectroscopy. Further, BA-PADPA was polymerized into polybenzoxazine by thermal curing. During the thermally induced polymerization, the imino group of PADPA segment first catalyzed the ring-opening reaction of benzoxazine groups of BA-PADPA at about $161{ }^{\circ} \mathrm{C}$. Subsequently, the autocatalytic benzoxazine polymerization process followed at higher temperatures. Both the curing stages of BA-PADPA were completed at lower temperature ranges than those of the bisphenol A/aniline-based benzoxazine (BAAN). The activation energies for the amine-catalyzed ring-opening and the autocatalytic benzoxazine polymerization were determined by both the Kissinger's and Ozawa's methods. Furthermore, the redox behavior of the as-synthesized BA-PADPA polymer (PBA-PADPA) was evaluated by cyclic voltammetry. The results indicated that the PBA-PADPA coating exhibited a satisfactory corrosion resistance ability with a corrosion rate of $0.0108 \mathrm{~mm}$ per year for carbon steel Q235, which is significantly lower than that of the BA-AN polymer coating (PBA-AN). Insights were gained into the anticorrosion mechanism, which indicated that the redox catalytic property of the PADPA segments in PBA-PADPA was probably capable of inducing the formation of a metal oxide layer composed of $\mathrm{Fe}_{2} \mathrm{O}_{3}$ on the steel surface, which was characterized by scanning electron microscopy and X-ray photoelectron spectroscopy. This study provides in-depth investigations and comprehensive understanding of the polymerization behavior of the benzoxazine/aniline-dimer-based system, which are necessary for the design, manufacture, and utilization of this type of high-performance polymeric coating.
\end{abstract}

Received 14th October 2017 Accepted 30th November 2017

DOI: 10.1039/c7ra11349h

rsc.li/rsc-advances lead to the achievement of more enhanced and/or specific performance for monomeric benzoxazines and their corresponding polybenzoxazines which open great opportunities for their practical applications. For instance, incorporation of sulfonic acid into benzoxazine backbone was achieved by simple molecular design and the resulting polybenzoxazine exhibited good acid resistance, thermal stability, and a low methanol permeability, thus acting as promising material for proton exchange membrane in direct methanol fuel cells. ${ }^{8}$ Moreover, the introduction of different functional groups other than the benzoxazine structure may result in various polymerization mechanisms, inducing multiple thermal events and/or influencing the initial polymerization temperature. This allows benzoxazines to build fundamentally different network structure, polymerization kinetics, and processing control from simple benzoxazines resins. According to literature, the cyanate ester functionalized benzoxazine monomer experienced two thermal events attributed to the cyclotrimerization of cyanate ester and the ring-opening polymerization of benzoxazine. The cyanate ester reaction stimulated the polymerization of benzoxazine; therefore, its polymerization temperature was significantly lower than typical range encountered during
College of Materials Science and Engineering, Southwest Petroleum University, Chengdu 610050,China.E-mail: polychem@swpu.edu.cn; yuntaoli@swpu.edu.cn 
benzoxazine polymerization. ${ }^{9}$ Moreover, primary aminefunctional benzoxazine monomers also exhibit multiple exothermic events corresponding to the reactions between the primary amine group and benzoxazine structure in addition to the typical cationic ring-opening polymerization of benzoxazine group. ${ }^{10}$ Furthermore, copolymerization of benzoxazines with other reactive compounds is also an effective method for the functionalization of polybenzoxazines. Remarkably high reactivity of benzoxazine compounds leads to the significant development of more polybenzoxazines blends with attractive properties, making them more interesting for structural applications. For example, polybenzoxazine-crosslinked aniline oligomers exhibited good corrosion resistance. ${ }^{11}$ Sulfur-rich polybenzoxazine copolymers showed potential application as the cathode material in $\mathrm{Li}-\mathrm{S}$ batteries. ${ }^{12,13}$

Polyaniline (PANI) and its derivatives have been widely explored and applied for tissue engineering biomaterials, ${ }^{\mathbf{1 4 , 1 5}}$ electrochemical sensors, ${ }^{16,17}$ and corrosion inhibitors ${ }^{18,19}$ attributed to their reversible redox capacity, nontoxic property, good environmental stability, facile synthesis, and low cost. Aniline oligomers show better solubility, fewer structural defects, and electroactivity comparable to the polymer, ${ }^{20,21}$ which make them promising candidates for high performance applications over the original high-molecular-weight PANI. However, anilinederived materials exhibit limited practical applications because of their poor processability. Therefore, an effective approach to fabricate high-performance aniline-derived materials involves the blending of PANI and its derivatives in polymeric resin, which integrates the good mechanical property of the polymeric resin with the electroactivity of the aniline segments. Therefore, the blend of benzoxazine with PANI and/or its derivatives is expected to be a promising research subject involving the systematic exploration of the preparation of aniline-based materials with significant balance among electrical, chemical, and mechanical properties. Furthermore, according to literature, polybenzoxazine-crosslinked PANI and oligoanilines exhibit excellent corrosion protection efficiency for carbon steel substrates ascribed to the synergistic effect of the low water absorption ability due to the polybenzoxazines and the excellent redox capacity due to the aniline counterparts. ${ }^{22}$ In addition to the satisfactory anticorrosion performance, noteworthy, the blends of maleimide containing polybenzoxazine (MI-Bz) and an amine-capped aniline trimer (ACAT) samples (MI-Bz/ACAT) exhibited a significantly reduced initial polymerization temperature of the benzoxazine groups at around $170{ }^{\circ} \mathrm{C}$, compared to the neat maleimide-containing polybenzoxazine compound. A systematic study involving the investigation of the effect of the introduction of primary amine group on the ring-opening polymerization of benzoxazine monomers was also reported by Agag et al. ${ }^{23}$ Unlike the single exotherm corresponding to the polymerization of the benzoxazine groups in the differential scanning calorimetry (DSC) thermograms of MI-Bz/ACAT, three exothermic peaks were observed in the case of primary aminefunctional benzoxazine monomer $\left(\mathrm{P}-\mathrm{a}-\mathrm{NH}_{2}\right)$. It is thus speculated that several thermal events are possibly attributed to the amine-catalyzed benzoxazine polymerization which involves locally heterogeneous reactions and/or multistage consumption of the amine. Sun et al. reported the use of five commercially available amines as nucleophilic hardeners for bisphenol-A type benzoxazine monomer (BA-a) in order to efficiently decrease the curing temperature and accelerate the cure rate.$^{24}$ Furthermore, an amine-catalyzed benzoxazine polymerization mechanism triggered by the nucleophilic substitution at the carbon atom $(\mathrm{O}-$ $\mathrm{C}-\mathrm{N}$ ) in the oxazine ring by the amine has also been proposed and verified. Nonetheless, benzoxazine containing aniline group on the same molecule could be prepared to circumvent the addition of extra hardeners with the objective of achieving better processability with lower polymerization temperature. The polymerization mechanism of benzoxazine/aniline system is still not completely understood and is expected to be continuously discussed based on systematic explorations.

Therefore, the main objective of the current study was to develop an electroactive aniline-dimer-based benzoxazine system with reduced polymerization temperature by a facile and effective method. Further, its polymerization behavior and mechanism were also systematically investigated. In this study, a novel electroactive aniline-dimer-functional benzoxazine monomer (BA-PADPA) was synthesized from aniline dimer $p$ aminodiphenylamine (PADPA), paraformaldehyde, and bisphenol A. PADPA was selected as the amine group because of the following reasons. First, it was an objective of current study to prepare monomeric benzoxazine containing aniline group on the same molecule based on flexible molecular design rather than employing aniline derivatives as extra hardeners or fillers. However, primary amine reacts with formaldehyde to form a triaza structure during the synthesis of the monomeric benzoxazine, which makes the one-step synthesis of a primary amine-functionalized benzoxazine quite difficult. In contrast, the imino group does not get involved in such reactions; nevertheless it shows the equal ability of nucleophilic substitution at the carbon atom $(\mathrm{O}-\mathrm{C}-\mathrm{N})$ in the oxazine ring, which may catalyze polymerization of benzoxazine monomer. Consequently, one-step synthesis process of PADPA-derived benzoxazine can be efficiently achieved. The imino group between aromatic rings in PADPA participates in the ring-opening reaction of benzoxazine groups by an oxygen protonation mechanism. Second, unlike other oligoanilines, PADPA does not undergo quinoid ring reaction or self-polymerization to form a PANI structure upon heating. Thus, minimal distractions of the thermally induced reactions in benzoxazine/aniline-derived system can be achieved. Third, the electroactivity of commercially available PADPA is comparable to that of the other aniline derivatives with higher molecular weight. Consequently, the incorporation of PADPA in benzoxazine structure may endow the material with desired electroactivity, thus expanding its functional applications. The molecular structure of the BAPADPA sample was characterized by ${ }^{1} \mathrm{H}-\mathrm{NMR},{ }^{13} \mathrm{C}-\mathrm{NMR}$, and fourier transform infrared (FTIR) spectroscopy. The curing behavior and interactions between benzoxazine group and amino group under the thermal curing process were evaluated by DSC and temperature-dependent FTIR spectroscopy. The electroactivity of the PADPA-functionalized polybenzoxazine, including their anticorrosion properties, was also evaluated. 


\section{Results and discussion}

\subsection{Synthesis and characterization of benzoxazine}

The BA-PADPA was prepared from PADPA, paraformaldehyde, and bisphenol A. FTIR, ${ }^{1} \mathrm{H}-\mathrm{NMR}$, and ${ }^{13} \mathrm{C}-\mathrm{NMR}$ spectroscopy were used to characterize its molecular structure. Fig. 1 shows the FTIR spectra of the BA-PADPA, clearly exhibiting the characteristic absorption band at $943 \mathrm{~cm}^{-1}$ assigned to the out-ofplane $\mathrm{C}-\mathrm{H}$ stretch of benzene attached to oxazine. The peaks at 1226 and $1033 \mathrm{~cm}^{-1}$ are, respectively, attributed to asymmetric and symmetrical $\mathrm{C}-\mathrm{O}-\mathrm{C}$ stretching. ${ }^{25}$ The peak at $827 \mathrm{~cm}^{-1}$ corresponds to the antisymmetric C-N-C asymmetric stretching vibration. Furthermore, the peak at $3392 \mathrm{~cm}^{-1}$ is assigned to the $\mathrm{N}-\mathrm{H}$ stretching vibration ${ }^{26}$ of PADPA.

Fig. 2 exhibits the ${ }^{1} \mathrm{H}$ NMR spectrum, showing that the two characteristic resonances at 4.52 and $5.27 \mathrm{ppm}$ are ascribed to $\mathrm{Ar}-\mathrm{CH}_{2}-\mathrm{N}-$ and $-\mathrm{O}-\mathrm{CH}_{2}-\mathrm{N}-$ protons, respectively. The signals of aromatic protons are within the typical range of 6.69$7.04 \mathrm{ppm}$. Notably, the resonance attributed to the imino group of PADPA exists within the range of 7.19-7.24. ${ }^{27,28}$ Furthermore, the carbon resonance signals due to $\mathrm{O}-\mathrm{CH}_{2}-\mathrm{N}$ and $\mathrm{Ar}-\mathrm{CH}_{2}-\mathrm{N}$ are, respectively, observed at 78.98 and $50.08 \mathrm{ppm}$ in ${ }^{13} \mathrm{C}-\mathrm{NMR}$ spectrum as shown in Fig. 3 to confirm the formation of the benzoxazine ring.

\subsection{Thermally induced reactions of BA-PADPA}

The cross-linking process was studied by DSC as shown in Fig. 4. DSC thermogram of bisphenol A/aniline-derived benzoxazine monomer (hereafter abbreviated as BA-AN) was also presented as a control. The samples were scanned at a heating rate of $10{ }^{\circ} \mathrm{C} \mathrm{min}^{-1}$. Clearly, the figure shows that BA-AN exhibits only one exothermic peak; however, BA-PADPA displays two overlapped exothermic peaks. Two exothermic peaks are observed with the maxima at 192.98 and $232.73{ }^{\circ} \mathrm{C}$, and the initial curing temperature of the first peak is around $161{ }^{\circ} \mathrm{C}$ in BA-PADPA. In particular, both curing stages of BAPADPA appeared at lower temperature ranges than those of the BA-AN. Furthermore, it has also been reported that the use of five commercially available amines as hardeners for BA-a could efficiently decrease the curing temperature by an aminecatalyzed benzoxazine polymerization mechanism triggered by

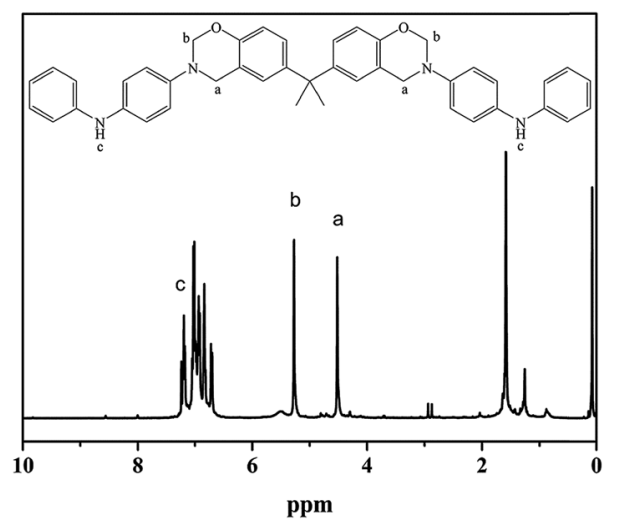

Fig. $2{ }^{1} \mathrm{H}$ NMR of BA-PADPA.

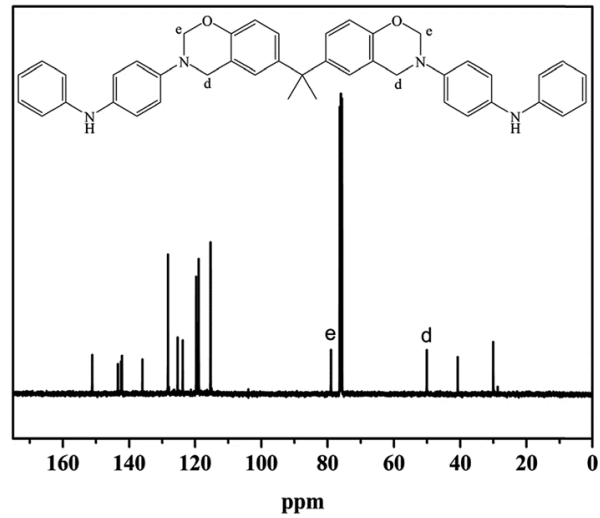

Fig. $3{ }^{13} \mathrm{C}$ NMR of BA-PADPA.

the nucleophilic substitution at the carbon atom $(\mathrm{O}-\mathrm{C}-\mathrm{N})$ in the oxazine ring. ${ }^{24}$ Thus, it was suggested that the imino group in PADPA might promote the benzoxazine ring-opening polymerization and that the curing reaction of BA-PADPA might have two cure stages. The curing reaction that occurred at lower temperature was named as reaction 1 and the one occurring at higher temperature was named as reaction 2 .

The reactions of the samples corresponding to the exothermic events were evaluated by temperature-dependent



Fig. 1 FTIR spectra of BA-PADPA.

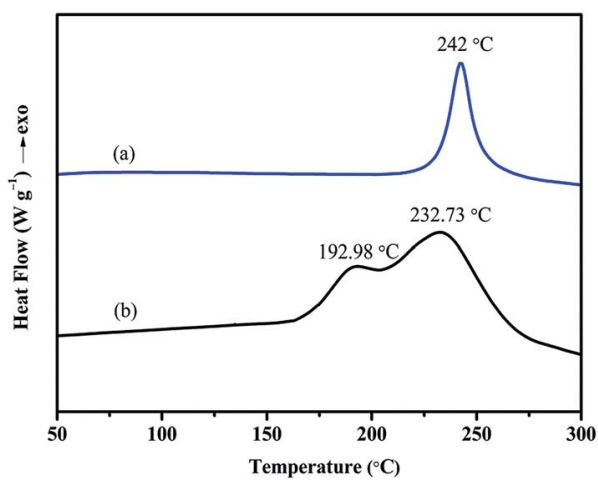

Fig. 4 DSC thermograms of (a) BA-AN and (b) BA-PADPA. 
FTIR spectroscopy. Fig. 5 shows that the absorption bands of the oxazine ring structure at $940 \mathrm{~cm}^{-1}$ (out-of-plane $\mathrm{C}-\mathrm{H}$ stretch of benzene attached to oxazine), $1226 \mathrm{~cm}^{-1}$ (asymmetric $\mathrm{C}-\mathrm{O}-\mathrm{C}$ stretching), and $1033 \mathrm{~cm}^{-1}$ (symmetrical C-O-C stretching) begin to decrease when temperature exceeds $160{ }^{\circ} \mathrm{C}$, which indicates the formation of an open-linear chain structure transformed from a closed-ring structure. Moreover, the increase in the intensity of the peak located at $3537 \mathrm{~cm}^{-1}$ corresponding to the $\mathrm{OH}-\mathrm{O}$ intramolecular hydrogen bonding ${ }^{29}$ in this temperature range provided further support for the ringopening polymerization process in this study. Thus, the results indicate that the first exotherm corresponds to the ringopening polymerization of benzoxazine. Moreover, the absorption peak at $3392 \mathrm{~cm}^{-1}$ is assigned to the $\mathrm{N}-\mathrm{H}$ stretching vibration of the imino group derived from PADPA. The intensity of the peak decreases gradually at temperatures between 150 and $210{ }^{\circ} \mathrm{C}$, which indicates the consumption of the imino group at this temperature range. It is likely that the imino group might have participated in the ring-opening reaction of the benzoxazine groups, leading to significantly reduced initial curing temperature. As discussed above, an amine-catalyzed benzoxazine polymerization mechanism triggered by the nucleophilic substitution at the carbon atom $(\mathrm{O}-\mathrm{C}-\mathrm{N})$ in the oxazine ring by the amine group could be applicable to the above mentioned reaction. Noteworthy, a new peak located at $1363 \mathrm{~cm}^{-1}$ in this temperature range might be attributed to $\mathrm{N}-\mathrm{C}-\mathrm{N}$ bond stretching ${ }^{2}$ formed during the nucleophilic attack of the amine toward the benzoxazine. Overall, the first exothermic peak in the DSC thermogram of BA-PADPA might correspond to the polymerization of benzoxazine catalyzed by the imino group of the PADPA.

The in situ FTIR spectra were recorded to trace the reactions corresponding to the second exothermic peak above $210{ }^{\circ} \mathrm{C}$ (Fig. 6). The absorption bands of oxazine ring at 940 and $1240 \mathrm{~cm}^{-1}$ gradually decrease with the increasing temperature and disappear when the temperature reaches $270{ }^{\circ} \mathrm{C}$, which indicates completion of the ring opening reaction of the $\mathrm{BA}-$ PADPA. Furthermore, there is no change in the intensity of the peak around $3392 \mathrm{~cm}^{-1}$ which corresponds to the $\mathrm{N}-\mathrm{H}$ stretching vibration of the imino group in PADPA. This

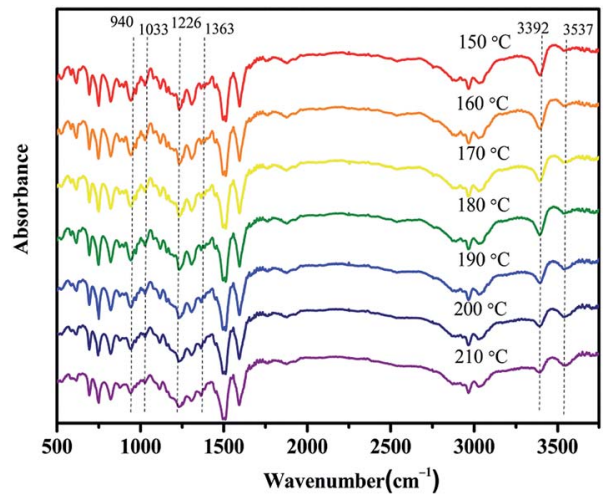

Fig. 5 Temperature-dependent FTIR spectra recorded on BA-PADPA during heating between 150 and $210^{\circ} \mathrm{C}$.

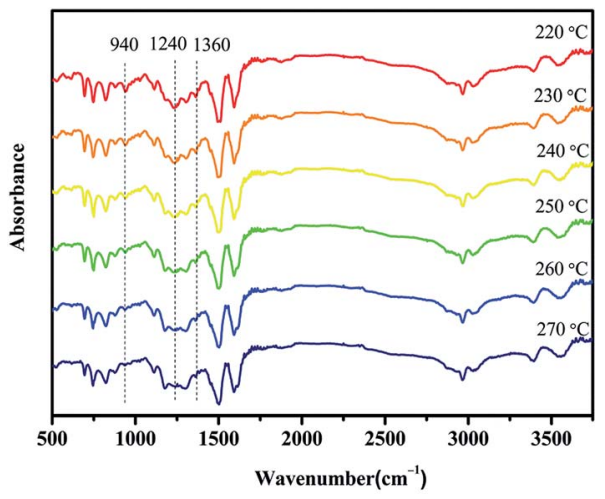

Fig. 6 Temperature-dependent FTIR spectra recorded on BA-PADPA during heating between 220 and $270{ }^{\circ} \mathrm{C}$.

indicates that the imino group was not involved in the ringopening reaction of the benzoxazine groups at this stage. Moreover, the absorption band of $\mathrm{CH}_{2}$ wagging vibration at $1360 \mathrm{~cm}^{-1}$ gradually decreases by heating at elevated temperature, which indicates the decomposition of intermediate formed during the amine-catalyzed benzoxazine polymerization to an iminium ion. The iminium ions were expected to participate in an electrophilic substitution reaction with the aromatic ring to form a more stable structure. Consequently, it is likely that the second exothermic peak in the DSC thermogram of BAPADPA might correspond to the thermally accelerated benzoxazine polymerization and that the ring opening polymerization proceeds by the general accepted mechanism.

Based on the results discussed above, possible reaction mechanism of BA-PADPA proposed for the thermally induced curing reactions at different stages and corresponding polymeric structures are illustrated in Scheme 1. Different polymeric structures are expected in the cured product of BAPADPA. Overall, BA-PADPA undergoes two different crosslinking processes during the thermally induced curing reactions, namely, amine-catalyzed polymerization followed by the autocatalytic polymerization of benzoxazine. Both these reactions can occur at relatively lower temperature compared to the original benzoxazine without amino groups.

The kinetics of the curing reaction is of vital importance for the optimum use of the resin and the in-depth study of the curing process. Nonisothermal DSC scans at different heating rates, i.e., $2.5,5,10,15$, and $20{ }^{\circ} \mathrm{C} \mathrm{min}^{-1}$, were recorded as shown in Fig. 7. With elevated heating rate, gradual increase in the peak temperatures can be clearly observed, which might be attributed to a delayed effect at higher heating rates. The peak temperatures of the multiple exothermic peaks corresponding to different heating rates can be used to determine the activation energy by the Kissinger and Ozawa methods. ${ }^{30,31}$ Fig. 8 and 9, respectively, present the Kissinger and Ozawa plots of the two exotherms. The average activation energies calculated from the corresponding slopes are summarized in Table 1 . The average activation energies of BA-PADPA for reactions 1 and 2 are in the range of 68.88-77.02 and 138.04-145.85 $\mathrm{kJ} \mathrm{mol}^{-1}$, respectively. These two approaches are based on different assumptions. 


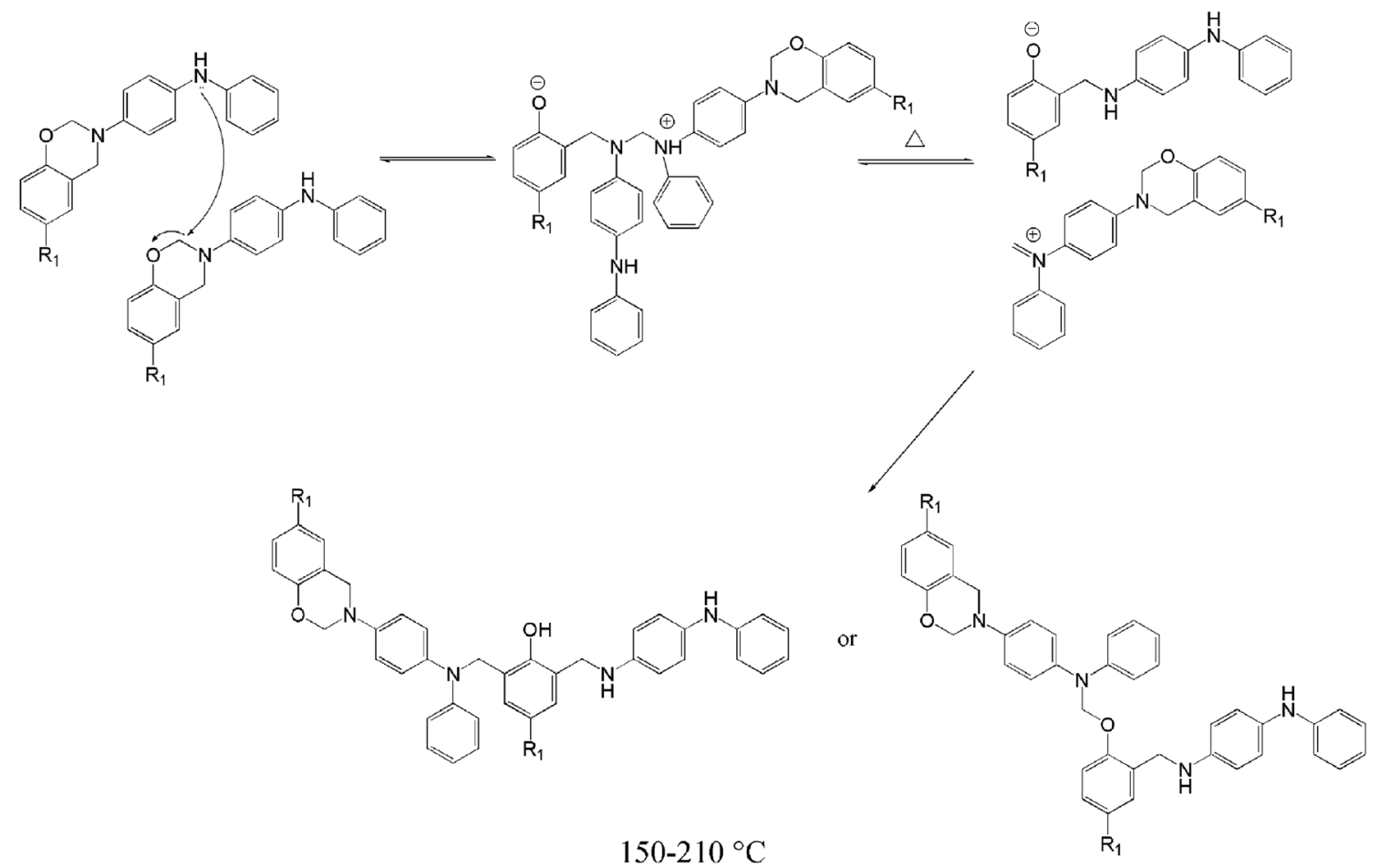<smiles>[R]c1ccc2c(c1)CN(c1ccc(Nc3ccccc3)cc1)CO2</smiles>

$150-210{ }^{\circ} \mathrm{C}$

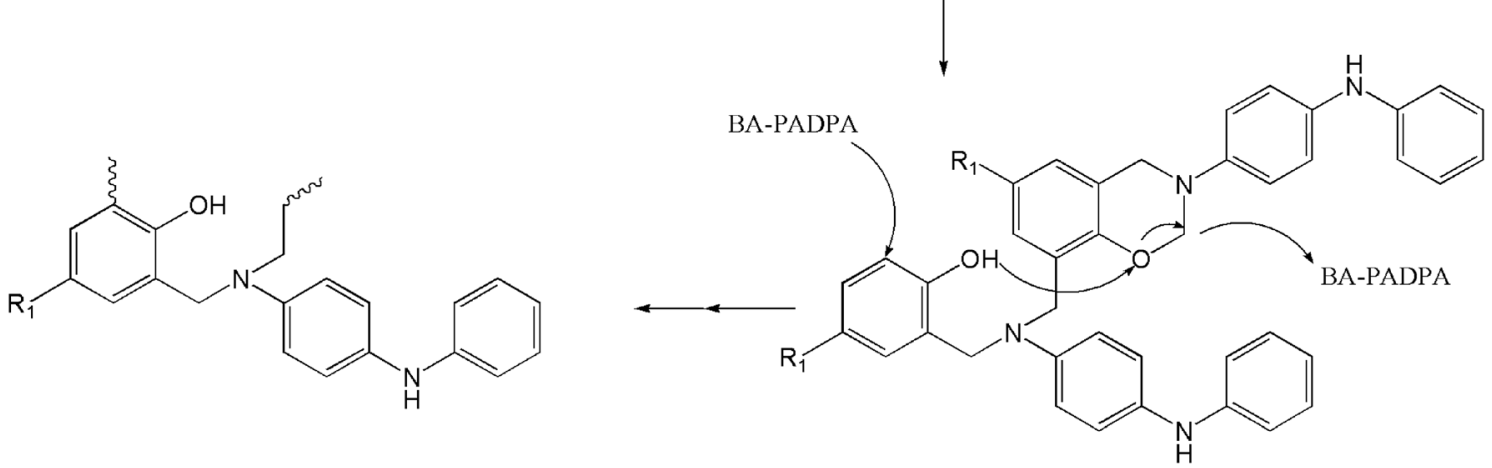

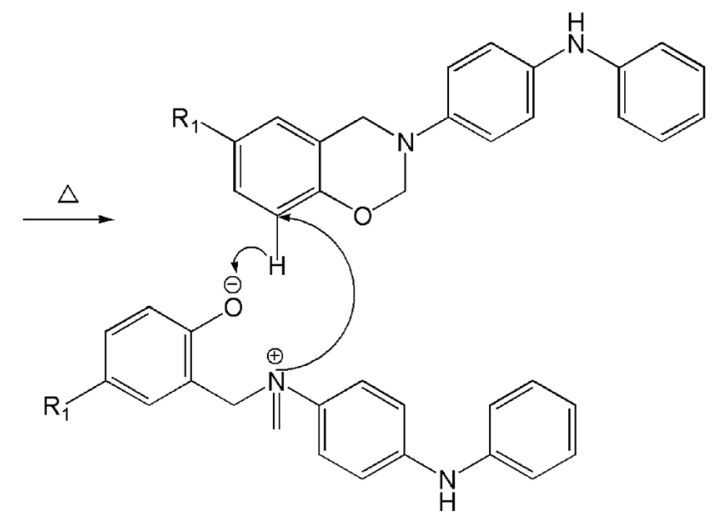

$220-270{ }^{\circ} \mathrm{C}$

Scheme 1 Possible reaction mechanism of BA-PADPA proposed for the thermally induced curing reactions at different stages.

Consequently, it can be observed that the value of activation energy calculated from the Kissinger method is slightly greater than that from the Ozawa method. Moreover, the activation energy of reaction 2 is significantly higher than that of reaction
1 , indicating that the amine-catalyzed benzoxazine polymerization is more sensitive to temperature than the autocatalytic polymerization..$^{32}$ Furthermore, the value of activation energy of reaction 2 is beyond the range of activation energy for 


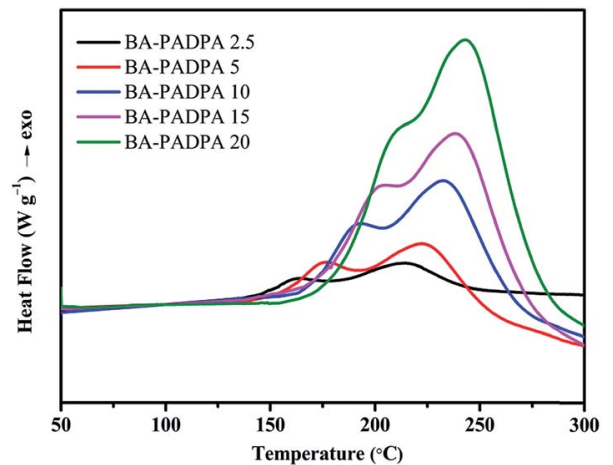

Fig. 7 DSC thermograms of BA-PADPA at different heating rates.

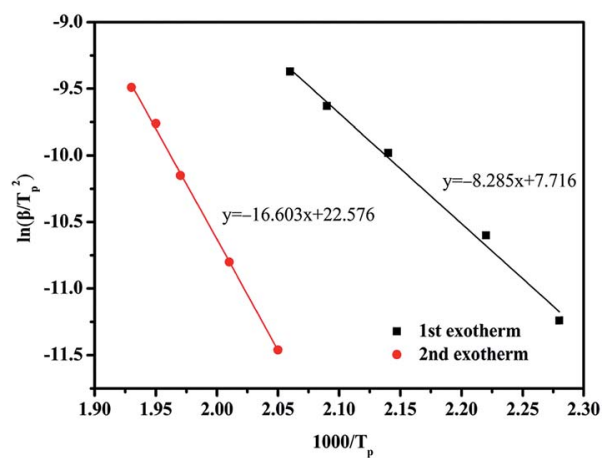

Fig. 8 Kissinger plot for determination of the activation energy of BAPADPA.

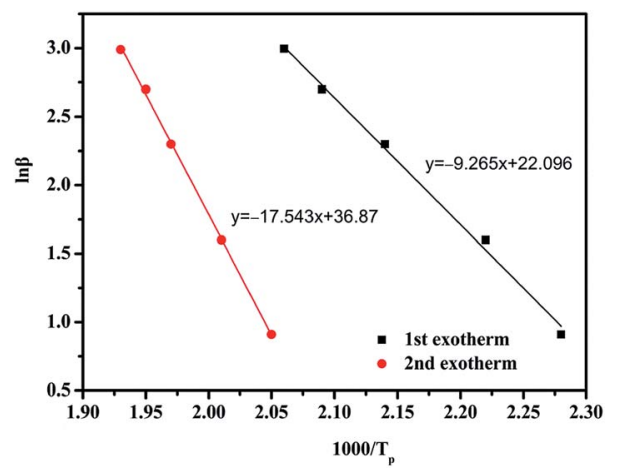

Fig. 9 Ozawa plot for determination of the activation energy of BAPADPA.

bifunctional benzoxazines. ${ }^{9}$ Therefore, it is suspected that the incorporation of PADPA structure into benzoxazine backbone increases the complexity of the curing reaction process.

\subsection{Electroactivity and anticorrosion performance}

The electroactivity of BA-PADPA polymer (PBA-PADPA) and BAAN polymer (PBA-AN) was investigated by cyclic voltammetry (CV) at a scan rate of $50 \mathrm{mV} \mathrm{s}^{-1}$ in $1.0 \mathrm{M} \mathrm{H}_{2} \mathrm{SO}_{4}$. Fig. 10(a) shows that PBA-PADPA displays one reversible redox couple at 0.602 / $0.454 \mathrm{~V}$, corresponding to the conversion between the neutral
Table 1 Activation energy of BA-PADPA calculated by Kissinger's and Ozawa's methods

\begin{tabular}{|c|c|c|}
\hline & \multicolumn{2}{|c|}{ Activation energy $\left(E_{\mathrm{a}}, \mathrm{kJ} \mathrm{mol}{ }^{-1}\right)$} \\
\hline & Kissinger's plot & Ozawa's plot \\
\hline First exotherm & 68.88 & 77.02 \\
\hline Second exotherm & 138.04 & 145.85 \\
\hline
\end{tabular}

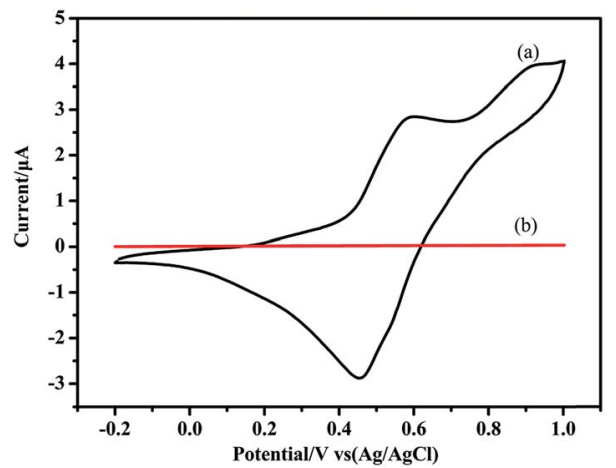

Fig. 10 Cyclic voltammograms of (a) PBA-PADPA and (b) PBA-AN at a scan rate $50 \mathrm{mV} \mathrm{s}^{-1}$.

form and the radical cation form. However, Fig. 10(b) shows that no such electrochemical response was observed for PBAAN. It is likely that the PADPA segment was responsible for the electroactivity of the PBA-PADPA.

Furthermore, PBA-PADPA and PBA-AN were coated on the surface of carbon steels to evaluate their anticorrosion properties. Fig. 11 exhibits the Tafel plots measured in $3.5 \mathrm{wt} \%$ aqueous $\mathrm{NaCl}$ solution. The corrosion potential $\left(E_{\text {corr }}\right)$ and the corrosion current $\left(I_{\text {corr }}\right)$ were obtained by the extrapolation method. The polarization resistances $\left(R_{\mathrm{p}}\right)$ and the corrosion rate $\left(R_{\text {corr }}\right)$ were calculated from $E_{\text {corr }}$ and $I_{\text {corr }}$ by using the previously reported formula ${ }^{33,34}$ (Table 2). The $I_{\text {corr }}$ of metal substrate decreased from 82.36 to $3.46 \mu \mathrm{A} \mathrm{cm}^{-2}$ due to the barrier property of PBA-AN coating. PBA-PADPA coating exhibited a relatively low value of $I_{\text {corr }}$, i.e. $0.93 \mu \mathrm{A} \mathrm{cm} \mathrm{cm}^{-2}$, which was much lower than that of the PBA-AN coating. Thus the PBA-PADPA coating

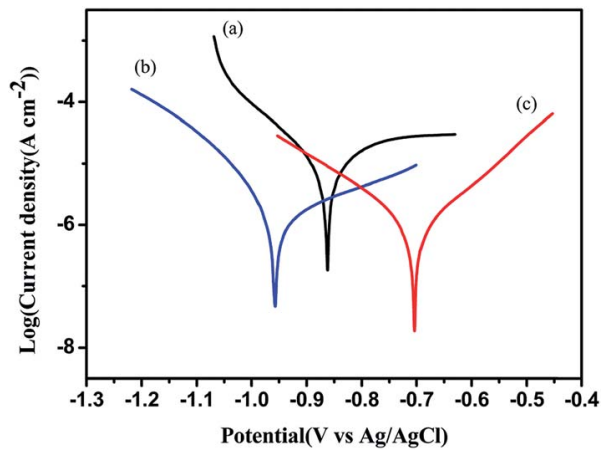

Fig. 11 Tafel plots for (a) metal substrate, (b) PBA-AN, (c) PBA-PADPA measured in $3.5 \mathrm{wt} \%$ aqueous $\mathrm{NaCl}$ solution. 
Table 2 Results of electrochemical corrosion measurements for different samples in $3.5 \mathrm{wt} \% \mathrm{NaCl}$ solutions

\begin{tabular}{|c|c|c|c|c|c|}
\hline Sample code & $E_{\text {corr }}(\mathrm{mV})$ & $R_{\mathrm{p}}\left(\mathrm{k} \Omega \mathrm{cm}^{2}\right)$ & $I_{\text {corr }}\left(\mu \mathrm{A} \mathrm{cm}{ }^{-2}\right)$ & $\begin{array}{l}R_{\text {corr }}(\mathrm{mm} \\
\text { per year })\end{array}$ & $R_{\text {ct }}\left(\mathrm{k} \mathrm{ohm} \mathrm{cm}^{2}\right)$ \\
\hline Metal substrate & -857.8 & 1.57 & 82.36 & 0.957 & 1.25 \\
\hline PBA-PADPA & -703.6 & 35.24 & 0.93 & 0.0108 & 52.2 \\
\hline
\end{tabular}

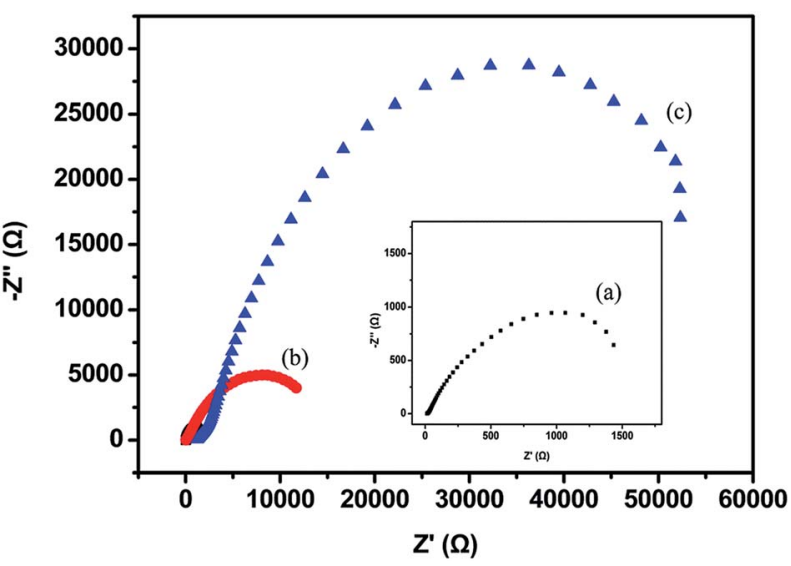

Fig. 12 Impedance diagrams for (a) metal substrate, (b) PBA-AN-, and (c) PBA-PADPA-coated stainless steel.

exhibited better anticorrosion behavior compared to the PBAAN coating due to the redox capacity of PBA-PADPA coating. Besides, the PBA-PADPA coating showed a more positive $E_{\text {corr }}$ value of $-703.6 \mathrm{mV}$ compared to that of the PBA-AN coating $(-958.3 \mathrm{mV})$ and bare steel $(-857.8 \mathrm{mV})$, indicating satisfactory corrosion protection ability of the PBA-PADPA. The active shift in $E_{\text {corr }}$ may have been caused by a decrease in the cathodic Tafel slope for the oxygen reaction from the point of kinetic factors. From the thermodynamics point of view, the positively shifted $E_{\text {corr }}$ may be attributed to a decrease in oxygen concentration at the metal surface because of the oxidation of the PBAPADPA by dissolved oxygen. Besides, an increase in the anodic Tafel slope which may be expected as a corrosion product film builds up on the steel electrode will shift the $E_{\text {corr }}$ in the noble direction. ${ }^{35}$ The PBA-AN coating exhibited more negative value of $E_{\text {corr }}$ than the bare steel, which may be ascribed to the lower cathodic polarization curve in a slightly changed anodic process. ${ }^{36}$ Furthermore, the declining tendency in $R_{\text {corr }}$ for metal substrate, PBA-AN coating, and PBA-PADPA coating (0.957, 0.0402 , and $0.0108 \mathrm{~mm}$ per year, respectively) also confirmed the better anticorrosive performance of PBA-PADPA coating. Moreover, the trend in $R_{\mathrm{p}}$ also supports the above mentioned discussion.

Electrochemical impedance spectroscopy (EIS) was used to further evaluate the anticorrosion behavior of the as-prepared polymeric coatings. Fig. 12 shows the Nyquist plot, clearly revealing that PBA-PADPA-coated carbon steel exhibits the maximum diameter of the semicircle, which confirms its better anticorrosion behavior compared to the PBA-AN coating. The charge transfer resistance $\left(R_{\mathrm{ct}}\right)$ was obtained by the equivalent electrical circuit fitting. ${ }^{37,38} R_{\text {ct }}$ is related to the diffusion of the corrosion reactants and interfacial reactions of the electrode; therefore, a higher $R_{\mathrm{ct}}$ value always corresponds to the better anticorrosion performance. PBA-PADPA-

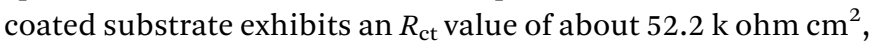
which is significantly higher than the value recorded for bare steel $\left(1.25 \mathrm{k} \mathrm{ohm} \mathrm{cm}^{2}\right)$ and PBA-AN-coated sample $(23.2 \mathrm{k}$ $\mathrm{ohm} \mathrm{cm}^{2}$ ). Thus, the analysis of the results obtained from EIS also confirmed the excellent corrosion resistance of the PBAPADPA coating.

\subsection{Observations and investigations of the steel surface}

The SEM images of the PBA-PADPA coating after immersion for 24 hours and the fresh coating were presented in Fig. 13. There is no roughening or peeling phenomenon at the surface of
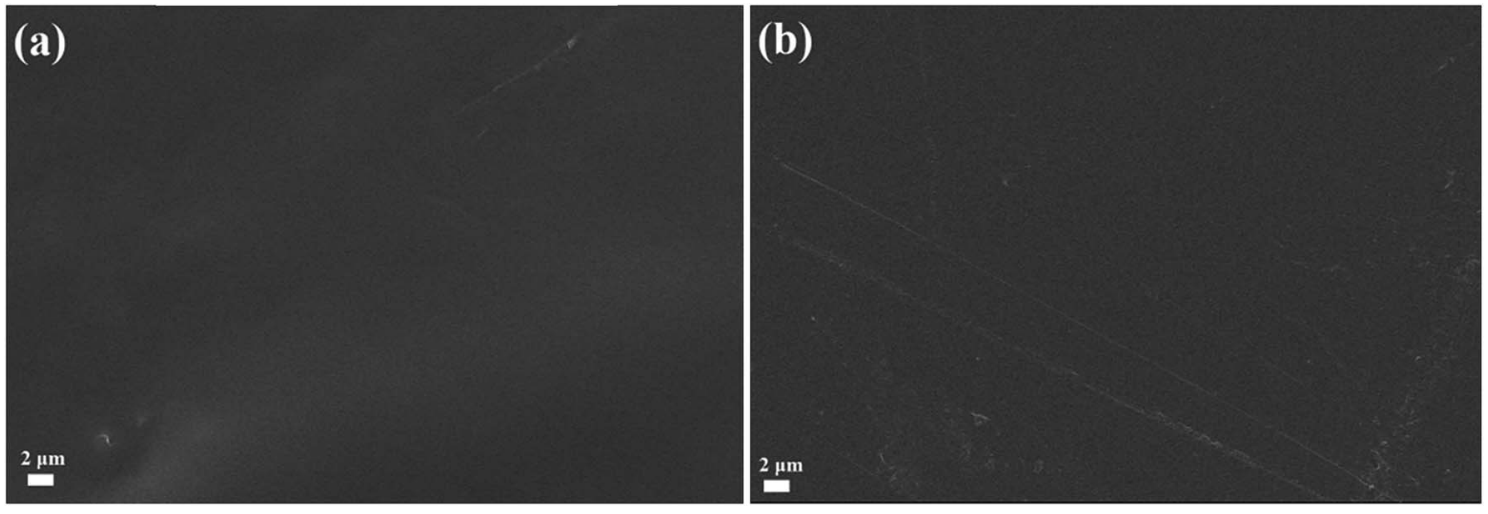

Fig. 13 SEM surface image of (a) fresh PBA-PADPA coating and (b) BA-PADPA coating after immersion for 24 hours. 
coating after immersion of 24 hours. Undeniably, the morphological change of the coatings is closely associated with the corrosion resistant performances, the negligible change reflects the good protection ability. After been immersed in $3.5 \mathrm{wt} \% \mathrm{NaCl}$ aqueous solution for $24 \mathrm{~h}$, the PBA-PADPA coatings were removed from the carbon steel. A grayish layer was deposited over the metal surface. SEM image (Fig. 14(b)) reveals the layer-by-layer stacking of the particles on the metal substrate. However, similar morphology was not observed for the bare metal surface (Fig. 14(a)). The scratches on the substrate were attributed to the pre-polishing using the sand papers.

Based on SEM images, the chemical nature of the passive metal oxide layer was identified by the X-ray photoelectron spectroscopy (XPS) investigation. XPS survey scans indicate the presence of $\mathrm{Fe}, \mathrm{O}$, and $\mathrm{C}$ elements (Fig. 15(a)). Fe 2p spectrum (Fig. 15(b)) shows that $\mathrm{Fe} 2 \mathrm{p}_{1 / 2}$ and $\mathrm{Fe} 2 \mathrm{p}_{3 / 2}$ binding energy appear at around 723.9 and $710.5 \mathrm{eV}$, respectively. The $2 p_{3 / 2}$ envelope was fitted well using the GS multiplets, highbinding-energy surface peak, and low-binding-energy prepeak. ${ }^{39}$ The result indicated that the oxide layer was composed of $\mathrm{Fe}_{2} \mathrm{O}_{3}$.

It is widely considered that the corrosive protection ability of the electroactive polymer and conducting polymers is attributed to their redox capacity. ${ }^{\mathbf{4 0 , 4 1}}$ The conjugated segment in the main chain could participate in the reactions taking place at the polymer-coated metal-electrolyte interface. Specifically, the aniline dimer segments could be reduced by capturing the electrons from the anodic dissolution of metal and take place the cathodic reaction, which suppresses the reaction of " $\mathrm{H}_{2} \mathrm{O}+$ $\mathrm{O}_{2}+4 \mathrm{e}^{-} \rightarrow 4 \mathrm{OH}^{-}$. The increasing Fe ions are transformed to the passive $\mathrm{Fe}_{2} \mathrm{O}_{3}$ as a passivation layer. In the meanwhile, the reduced PBA-PADPA can be reoxidized rapidly to its oxidation form by dissolved oxygen. ${ }^{42}$ The oxidized form is suggested to lead to oxidation of $\mathrm{Fe}$, thereby maintaining a protective oxide layer on Fe. Moreover, the imine groups on the PADPD backbone have been reported to absorb the Fe ions at the corrosive regions to form the $\mathrm{Fe}-\mathrm{NH}-$ chelated functional groups, which

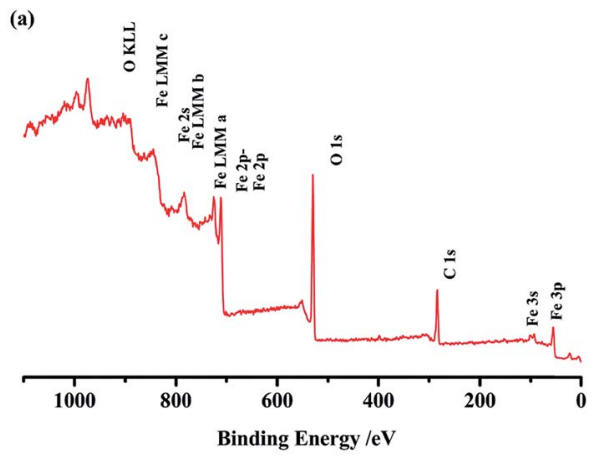

(b)

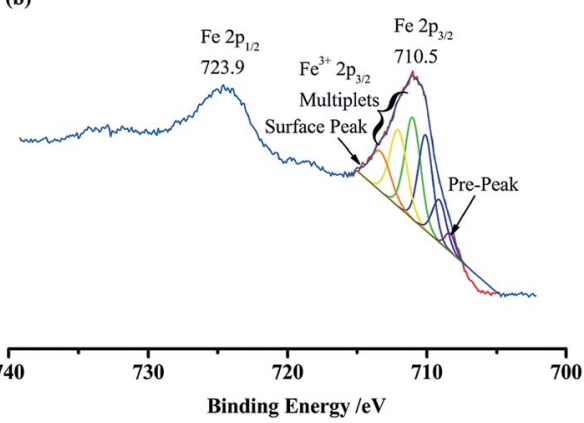

Fig. 15 XPS spectra of passivation oxide layer induced by PBAPADPA: (a) full survey spectrum and (b) Fe $2 \mathrm{p}$.

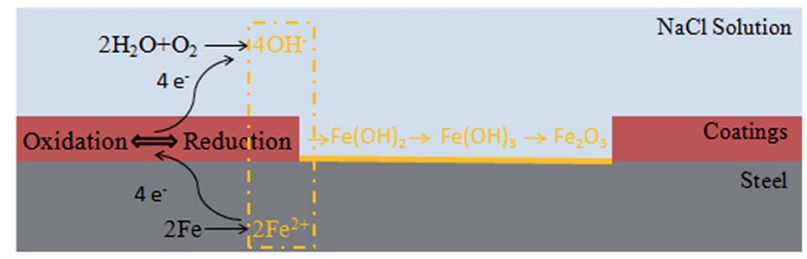

Fig. 16 Schematic representation of mechanism of carbon steel passivation by PBA-PADPA coatings.

may stabilize the potential of metal in the passive region. ${ }^{43}$ The anti-corrosive mechanism of PBA-PADPA coating is exhibited in Fig. 16.
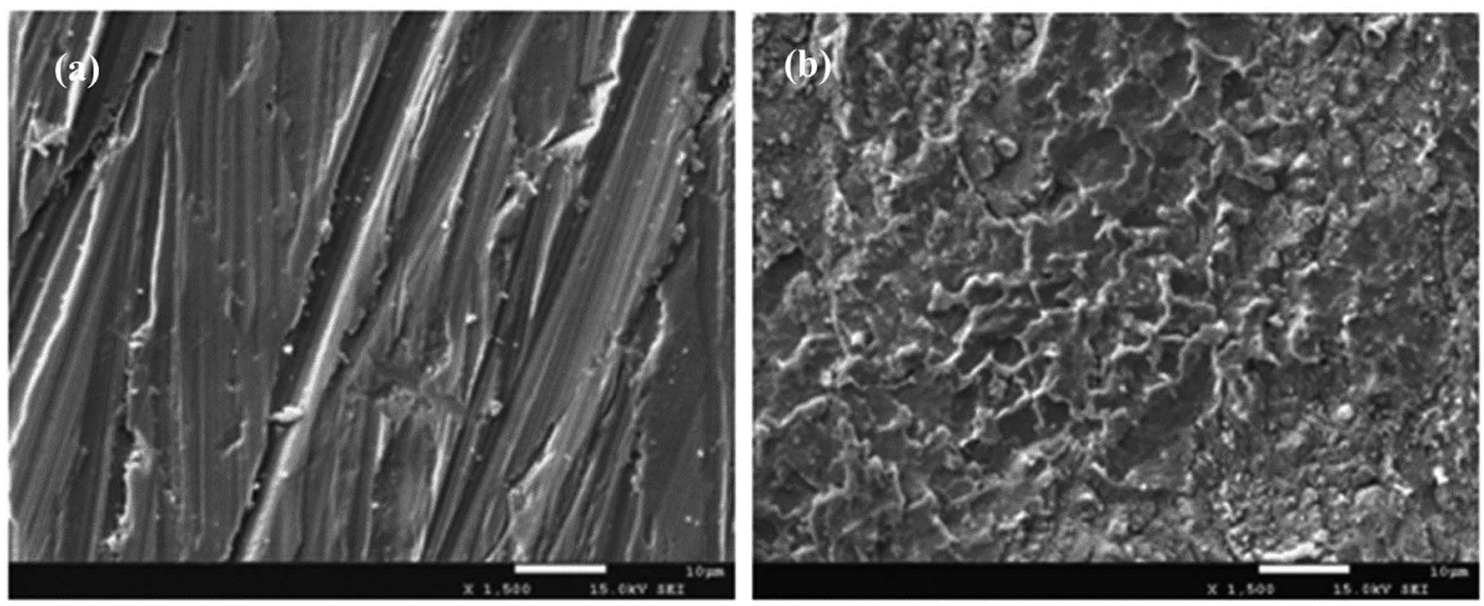

Fig. 14 SEM surface image of (a) polished steel and (b) steel induced by PBA-PADPA. 


\section{Conclusions}

We have successfully synthesized electroactive benzoxazine (BA-PADPA) by incorporation of aniline dimer in its structure. The resulting polybenzoxazine (PBA-PADPA) undergoes two different cross-linking processes during the thermally induced polymerization. The imino group PADPA is involved in the ringopening reaction of the benzoxazine groups, which results in the significantly reduced initial curing temperature. Autocatalytic polymerization of benzoxazine instead of the aminecatalyzed polymerization occurs at higher temperatures. Besides, PBA-PADPA shows reversible redox activity, making it suitable for advanced anticorrosive coatings. The incorporation of PADPA significantly enhances the corrosion protection performance of benzoxazine coating as proven by potentiodynamic polarization curves and EIS. The investigation of the morphology of corrosion products by SEM and the chemical nature characterization by XPS reveal that the addition of PADPA may facilitate the formation of a passive layer, consisting mainly of $\mathrm{Fe}_{2} \mathrm{O}_{3}$ on the steel surface. We expect this investigation of the polymerization behavior of aniline-dimer-based benzoxazine system and the facile preparation of electroactive polybenzoxaine could pave the way to develop highperformance polymeric coatings.

\section{Experimental section}

\subsection{Materials}

PADPA was purchased from Thermo Fisher Scientific Inc. China and was utilized as received without further purification. Bisphenol A (99.5\%), paraformaldehyde (95.0\%), sodium hydroxide (99.0\%), anhydrous sodium sulfate (99.0\%), sodium chloride $(99.0 \%)$, and all solvents were purchased from Chengdu Kelong Chemical Reagents Corp. and used as received. Bisphenol A/aniline-based benzoxazine XU 35610 (BAAN, Scheme 2(a)) was purchased from Huntsman Chemical and used as received. The BA-AN undergoes ring-opening polymerization process to form its corresponding polybenzoxazine resin (PBA-AN, Scheme 2(b)).

\subsection{Instruments}

The chemical structure of BA-PADPA was determined by FTIR spectroscopy (Nicolet 6700 with $\mathrm{KBr}$ pellet), and ${ }^{1} \mathrm{H}-\mathrm{NMR}$ and ${ }^{13} \mathrm{C}-\mathrm{NMR}$ spectroscopy performed on a Bruker AVANCE III HD 400 , using deuterated chloroform as the solvent. The thermallyinduced polymerization of BA-PADPA was characterized by in situ diffuse reflectance FTIR spectroscopy (in situ DRIFTS) performed using a Nicolet-560 IR spectrometer. Spectra were recorded every 18 seconds, with a heating rate of $5{ }^{\circ} \mathrm{C} \mathrm{min}^{-1}$. DSC tests were conducted using a DSC Q20 (TA Instruments) with nitrogen as the purge gas. $\mathrm{CV}$, potentiodynamic polarization, and electrochemical impedance spectroscopy (EIS) were performed on an Autolab PGSTAT302N equipment. $\mathrm{Ag} / \mathrm{AgCl}$ electrode (saturated $\mathrm{KCl}$ ) and Pt wire were, respectively, used as reference and counter electrodes. In linear polarization experiments, the potential was scanned at a scan rate of<smiles>CC(C)(c1ccc2c(c1)CN(c1ccccc1)CO2)c1ccc2c(c1)CN(c1ccccc1)CO2</smiles>

(a) BA-AN<smiles>CCCN(Cc1cc(C(C)(C)c2cc(C)c(O)c(CN(CCC)c3ccccc3)c2)cc(C)c1O)c1ccccc1</smiles>

(b) PBA-AN

Scheme 2 Chemical structure of (a) BA-AN and (b) PBA-AN.

$2 \mathrm{mV} \mathrm{s}^{-1}$ from $-250 \mathrm{mV}$ below to $+250 \mathrm{mV}$ above the corrosion potential. In impedance measurements, a $10 \mathrm{mV}$ perturbation accompanied by the frequency range of $100 \mathrm{kHz}$ to $0.01 \mathrm{~Hz}$ was applied. The surface of the steel substrate was sputter-coated with a conductive gold layer for morphological characterization by field-emission SEM (FESEM, JEOL JSM-7500F, Japan). The composition of the rust products formed on the substrate was analyzed by X-ray photon electron spectroscopy (XPS) using a Kratos XSAM800 spectrometer with aluminum as the exciting source.

\subsection{Synthesis of BA-PADPA}

A solution of paraformaldehyde (0.6 g, $20 \mathrm{mmol})$, bisphenol A $(1.71 \mathrm{~g}, 7.5 \mathrm{mmol})$, and PADPA $(1.84 \mathrm{~g}, 10 \mathrm{mmol})$ in toluene (150 $\mathrm{mL}$ ) was stirred in a $250 \mathrm{~mL}$ three-necked flask. The reaction was carried out at room temperature for $30 \mathrm{~min}$ at $50^{\circ} \mathrm{C}$ for $5 \mathrm{~h}$, and $110{ }^{\circ} \mathrm{C}$ for $3 \mathrm{~h}$. Subsequently, the reaction system was cooled down to room temperature and neutralized with aqueous solution of $\mathrm{NaOH}(0.1 \mathrm{M})$ and deionized water. The organic phase was dried with anhydrous $\mathrm{Na}_{2} \mathrm{SO}_{4}$ and then the solvent was evaporated in a rotary evaporator. Finally, the product was obtained as yellow powder (yield ca. 33\%). The synthesis route is presented in Scheme 3.

\subsection{Sample preparation and curing procedure}

The monomer solution was prepared by dissolving BA-PADPA and BA-AN, respectively, in dichloromethane $\left(0.5 \mathrm{mg} \mathrm{mL}^{-1}\right)$. Then, the solution was drop casted onto indium tin oxide (ITO) working electrodes and heated at $50{ }^{\circ} \mathrm{C}$ for $1 \mathrm{~h}$ to evaporate the solvent. Subsequently, the coated ITO substrate was cured at $180{ }^{\circ} \mathrm{C}$ for $2 \mathrm{~h}$ and then at $200{ }^{\circ} \mathrm{C}$ for $2 \mathrm{~h}$. The obtained PBAPADPA and PBA-AN coated electrodes were used for CV tests. For potentiodynamic polarization and EIS studies, the carbon steel Q235 $(10 \mathrm{~mm} \times 10 \mathrm{~mm} \times 1 \mathrm{~mm})$ was first degreased with 


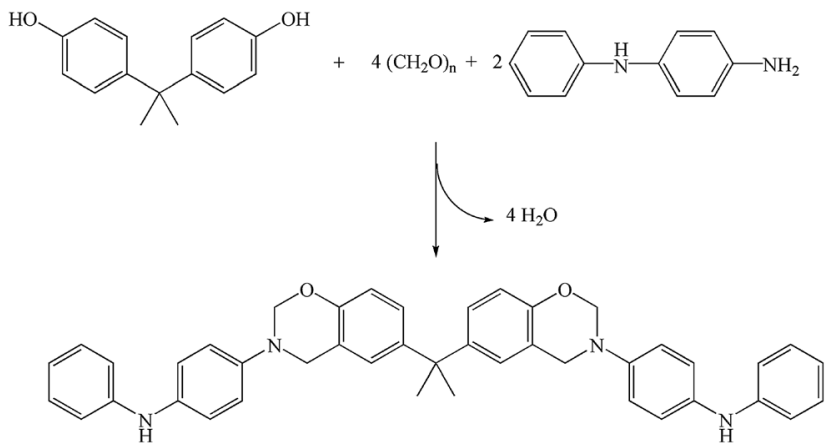

Scheme 3 Synthesis of BA-PADPA.

acetone and then coated with PBA-PADPA and PBA-AN, respectively, by following the same method previously used for the preparation of working electrodes in CV measurements. The PBA-PADPA and PBA-AN coatings on carbon steel is about a 5 $\mu \mathrm{m}$ thick by micrometer caliper.

\section{Conflicts of interest}

There are no conflicts to declare.

\section{Acknowledgements}

This work was financially supported by the National Natural Science Foundation (51703191) of China, the Scientific Research Innovation Team of University in Sichuan Province (16TD0009), P. R. China, the Innovative Training Program for College Students of China (201710615016), and the Foundation for Key Lab of Oil and Gas Material of Southwest Petroleum University (X151517KCL37), P. R. China.

\section{References}

1 T. Endo, Toward Elucidating the Role of Number of Oxazine Rings and Intermediates in the Benzoxazine Backbone on Their Thermal Characteristics, Macromolecules, 2016, 49(22), 8466-8478.

2 S. N. Kolanadiyil and M. Minami, Endo T. Synthesis and Thermal Properties of Difunctional Benzoxazines with Attached Oxazine Ring at the Para-, Meta-, and OrthoPosition, Macromolecules, 2017, 50(9), 3476-3488.

3 T. Urbaniak, M. Soto, M. Liebeke, et al., Insight into the Mechanism of Reversible Ring-Opening of 1,3-Benzoxazine with Thiols, J. Org. Chem., 2017, 82(8), 4050-4055.

4 E. B. Caldona, A. C. C. de Leon, P. G. Thomas, et al., Superhydrophobic rubber-modified polybenzoxazine/ $\mathrm{SiO}_{2}$ nanocomposite coating with anti-corrosion, anti-ice, and superoleophilicity properties, Ind. Eng. Chem. Res., 2017, 56(6), 1485-1497.

5 W. Zhang, X. Lu, Z. Xin, et al., Development of a superhydrophobic polybenzoxazine surface with selfcleaning and reversible water adhesion properties, RSC Adv., 2016, 6(108), 106054-106063.
6 S. C. Lin, C. S. Wu, J. M. Yeh, et al., Reaction mechanism and synergistic anticorrosion property of reactive blends of maleimide-containing benzoxazine and amine-capped aniline trimer, Polym. Chem., 2014, 5(14), 4235-4244.

7 C. Zhou, X. Lu, Z. Xin, et al., Hydrophobic benzoxazine-cured epoxy coatings for corrosion protection, Prog. Org. Coat., 2013, 76(9), 1178-1183.

8 B. Yao, X. Yan, Y. Ding, et al., Synthesis of sulfonic acidcontaining polybenzoxazine for proton exchange membrane in direct methanol fuel cells, Macromolecules, 2014, 47(3), 1039-1045.

9 S. Ohashi, J. Kilbane, T. Heyl, et al., Synthesis and characterization of cyanate ester functional benzoxazine and its polymer, Macromolecules, 2015, 48(23), 8412-8417.

10 T. Agag, C. R. Arza, F. H. J. Maurer, et al., Primary aminefunctional benzoxazine monomers and their use for amide-containing monomeric benzoxazines, Macromolecules, 2010, 43(6), 2748-2758.

11 S. C. Lin, C. S. Wu, J. M. Yeh, et al., Reaction mechanism and synergistic anticorrosion property of reactive blends of maleimide-containing benzoxazine and amine-capped aniline trimer, Polym. Chem., 2014, 5(14), 4235-4244.

12 M. Arslan, B. Kiskan and Y. Yagci, Combining elemental sulfur with polybenzoxazines via inverse vulcanization, Macromolecules, 2016, 49(3), 767-773.

13 S. Shukla, A. Ghosh, U. K. Sen, et al., Cardanol BenzoxazineSulfur Copolymers for Li-S batteries: Symbiosis of Sustainability and Performance, ChemistrySelect, 2016, 1(3), 594-600.

14 L. Huang, X. Zhuang, J. Hu, et al., Synthesis of biodegradable and electroactive multiblock polylactide and aniline pentamer copolymer for tissue engineering applications, Biomacromolecules, 2008, 9(3), 850-858.

15 J. Chen, B. Guo, T. W. Eyster, et al., Super stretchable electroactive elastomer formation driven by aniline trimer self-assembly, Chem. Mater., 2015, 27(16), 5668-5677.

16 J. Hu, X. Zhuang, L. Huang, et al., pH/potential-responsive large aggregates from the spontaneous self-assembly of a triblock copolymer in water, Langmuir, 2008, 24(23), 13376-13382.

17 W. Zhao, L. Glavas, K. Odelius, et al., Facile and green approach towards electrically conductive hemicellulose hydrogels with tunable conductivity and swelling behavior, Chem. Mater., 2014, 26(14), 4265-4273.

18 R. M. Bandeira, J. van Drunen, A. C. Garcia, et al., Influence of the thickness and roughness of polyaniline coatings on corrosion protection of AA7075 aluminum alloy, Electrochim. Acta, 2017, 240, 215-224.

19 C. W. Peng, K. C. Chang, C. J. Weng, et al., Nano-casting technique to prepare polyaniline surface with biomimetic superhydrophobic structures for anticorrosion application, Electrochim. Acta, 2013, 95, 192-199.

20 K. Junker, S. Luginbühl, M. Schüttel, et al., Efficient polymerization of the aniline dimer paminodiphenylamine (PADPA) with trametes versicolor laccase $/ \mathrm{O}_{2}$ as catalyst and oxidant and AOT vesicles as templates, ACS Catal., 2014, 4(10), 3421-3434. 
21 M. A. Cotarelo, F. Huerta, C. Quijada, et al., Synthesis and characterization of electroactive films deposited from aniline dimers, J. Electrochem. Soc., 2006, 153(7), D114-D122.

22 S. C. Lin, C. S. Wu, J. M. Yeh, et al., Reaction mechanism and synergistic anticorrosion property of reactive blends of maleimide-containing benzoxazine and amine-capped aniline trimer, Polym. Chem., 2014, 5(14), 4235-4244.

23 T. Agag, C. R. Arza, F. H. J. Maurer, et al., Primary aminefunctional benzoxazine monomers and their use for amide-containing monomeric benzoxazines, Macromolecules, 2010, 43(6), 2748-2758.

24 J. Q. Sun, W. Wei, Y. Z. Xu, et al., A curing system of benzoxazine with amine: reactivity, reaction mechanism and material properties, RSC Adv., 2015, 5(25), 19048-19057.

25 J. Dunkers and H. Ishida, Vibrational assignments of 3-alkyl3,4-dihydro-6-methyl-2H-1,3-benzoxazines in the fingerprint region, Spectrochim. Acta, Part A, 1995, 51(6), 1061-1074.

26 R. Yuan, S. Wu, P. Yu, et al., Superamphiphobic and Electroactive Nanocomposite toward Self-Cleaning, Antiwear, and Anticorrosion Coatings, ACS Appl. Mater. Interfaces, 2016, 8(19), 12481-12493.

27 T. Endo, Toward Elucidating the Role of Number of Oxazine Rings and Intermediates in the Benzoxazine Backbone on Their Thermal Characteristics, Macromolecules, 2016, 49(22), 8466-8478.

28 M. Yin, F. Li, Y. Yan, et al., Poly(aryl ether) bearing electroactive tetraaniline pendants and allyl groups: synthesis, photo-crosslinking and electrochemical properties, J. Polym. Sci., Part A: Polym. Chem., 2016, 54(15), 2321-2330.

29 H. D. Kim and H. Ishida, A study on hydrogen bonding in controlled-structure benzoxazine model oligomers, Macromol. Symp., 2003, 195(1), 123-140.

30 D. Zhang, J. Yue, H. Li, et al., Curing kinetics study of benzoxazine using diaryliodonium salts as thermal initiators, Thermochim. Acta, 2016, 643, 13-22.

31 J. Yue, C. Zhao, Y. Dai, et al., Catalytic effect of exfoliated zirconium phosphate on the curing behavior of benzoxazine, Thermochim. Acta, 2017, 650, 18-25.

32 C. Jubsilp, S. Damrongsakkul, T. Takeichi, et al., Curing kinetics of arylamine-based polyfunctional benzoxazine resins by dynamic differential scanning calorimetry, Thermochim. Acta, 2006, 447(2), 131-140.

33 T. W. Chuo, J. M. Yeh and Y. L. Liu, A reactive blend of electroactive polymers exhibiting synergistic effects on selfhealing and anticorrosion properties, RSC Adv., 2016, 6(60), 55593-55598.

34 Y. Yan, F. Li, A. M. Hanlon, et al., Electrochemical performance of electroactive poly(amic acid)- $\mathrm{Cu}^{2+}$ composites, Appl. Surf. Sci., 2017, 392, 1-7.

35 S. C. Dexter and G. Y. Gao, Effect of seawater biofilms on corrosion potential and oxygen reduction of stainless steel, Corros. Sci., 1988, 44(10), 717-723.

36 G. Song and D. StJohn, The effect of zirconium grain refinement on the corrosion behaviour of magnesium-rare earth alloy MEZ, J. Light Met., 2002, 2(1), 1-16.

37 C. Chen, S. Qiu, M. Cui, et al., Achieving high performance corrosion and wear resistant epoxy coatings via incorporation of noncovalent functionalized graphene, Carbon, 2017, 114, 356-366.

38 P. Montoya, C. R. Martins, H. G. de Melo, et al., Synthesis of polypyrrole-magnetite/silane coatings on steel and assessment of anticorrosive properties, Electrochim. Acta, 2014, 124, 100-108.

39 A. P. Grosvenor, B. A. Kobe, M. C. Biesinger, et al., Investigation of multiplet splitting of $\mathrm{Fe} 2 \mathrm{p}$ XPS spectra and bonding in iron compounds, Surf. Interface Anal., 2004, 36(12), 1564-1574.

40 S. Qiu, C. Chen, M. Cui, et al., Corrosion protection performance of waterborne epoxy coatings containing selfdoped polyaniline nanofiber, Appl. Surf. Sci., 2017, 407, 213-222.

41 C. W. Peng, C. Hsu, K. H. Lin, et al., Electrochemical corrosion protection studies of aniline-capped aniline trimer-based electroactive polyurethane coatings, Electrochim. Acta, 2011, 58, 614-620.

42 P. Li, T. C. Tan and J. Y. Lee, Corrosion protection of mild steel by electroactive polyaniline coatings, Synth. Met., 1997, 88(3), 237-242.

43 S. Qiu, C. Chen, W. Zheng, et al., Long-term corrosion protection of mild steel by epoxy coating containing selfdoped polyaniline nanofiber, Synth. Met., 2017, 229, 39-46. 